\title{
Practice Environment, Work Characteristics and Levels of Burnout as Predictors of Nurse Reported Job Outcomes, Quality of Care and Patient Adverse Events: A Study across Residential Aged Care Services
}

\author{
Peter Van Bogaert' ${ }^{1}$, Tinne Dilles ${ }^{1}$, Kristien Wouters ${ }^{2}$, Bart Van Rompaey ${ }^{1}$ \\ ${ }^{1}$ Departement of Nursing and Midwifery Sciences, Centre for Research and Innovation in Care (CRIC), Faculty of \\ Medicine and Health Sciences, University of Antwerp, Antwerp, Belgium \\ ${ }^{2}$ Department of Scientific Coordination, University Hospital Antwerp, Antwerp, Belgium \\ Email: peter.vanbogaert@uantwerpen.be, tinne.dilles@uantwerpen.be, kristien.wouters@uza.be, \\ bart.vanrompaey@uantwerpen.be
}

Received 19 January 2014; revised 19 March 2014; accepted 4 April 2014

Copyright $@ 2014$ by authors and Scientific Research Publishing Inc.

This work is licensed under the Creative Commons Attribution International License (CC BY). http://creativecommons.org/licenses/by/4.0/

(c) ()

\section{Abstract}

To understand how to create a stabile workforce achieving excellent quality of care and patient safety, associations between practice environments and nurse and patient outcomes have been widely studied in acute and psychiatric care hospitals. Knowing residential aged care services are challenged to tackle complex patients' needs within certain working conditions, to what extent do nurses perceive their practice environment in geriatric care? In a cross-sectional survey, a sample of 709 registered nurses, licensed practical nurses and nurse aides employed in 25 residential aged care services completed a structured questionnaire composed of various validated instruments measuring nurse practice environment factors, nurse work characteristics, burnout, nurse reported job outcomes, quality and patient adverse events. Associations between variables across residential aged care services were examined using multilevel modelling techniques. Associations were identified between practice environment factors, work characteristics, burnout dimensions, and reported outcome variables across residential aged care services. Multiple multilevel models showed independent variables (nursing management at the unit level, workload, decision latitude, social capital, emotional exhaustion and depersonalization) as important predictors of nurse reported outcome (job satisfaction, turnover intensions), quality of care (at the unit, the last shift, and in the service within the last year) and patient adverse events (patient and family complaints, patient falls, pulmonary and urinary tract infections, and medications errors). Results suggested 
the importance of nurse practice environment factors, nurse work characteristics and perception of burnout on nurse and patient outcomes across their nurse practice environment. Challenging the complex care of a vulnerable and frail population executives, physicians, nursing leaders as well as nurses in their nurse practice environment shared responsibility to create working conditions achieving excellent quality and patient safety.

\title{
Keywords
}

\author{
Burnout, Job Satisfaction, Nurse Practice Environment, Quality of Care, Residential Aged Care, \\ Multilevel Modelling
}

\section{Introduction}

Healthcare organizations are challenged to create a stabile workforce achieving excellent care and patient safety. A body of knowledge shows associations of nurse practice environments [1]-[7] and psychosocial work environments [8] [9] with quality of care and patient safety [10]-[13]. Most of these studies were performed in acute care hospitals and later replicated in psychiatric care hospitals [14]-[18]. To guide executives, (nurse) managers, physicians and nurses in their effort to improve patient care and conditions of care delivering for healthcare workers these evidences are essential. In particular, older adults within residential aged care services are a vulnerable and frail population and relevant knowledge and insights for their needs and how to deliver care are imperative.

A systematic review [19] of eight qualitative papers studying the experiences of registered nurses as clinical leaders and managers in residential aged care services described various barriers. A lack of professional support and collaboration from allied health and medical colleagues and a lack of specific education that is focused in clinical leadership and health team management were identified as barriers. In addition, the authors described an absence of current structured pathway of learning and development for nursing careers in aged care and strong organizational barriers in preventing continuing education and skills development for nurse leaders in aged care environments. Finally, nurses were strongly identified with their leadership role in residential aged care but experienced paradoxical feelings of being valued by the clients and devalued by the system at the same time. A study using the Agency Geriatric Nursing Care survey showed that perceived nurse quality of care in residential aged care services was better when care was based on evidence and specialised for the needs of older adults supporting their autonomy and independence [20]. Others studies investigated the role and motivation of nurse assistants, the major workforce in long-term settings. Nurse assistants were motivated to stay when the meaning of work emerged as an experience of family, pride and control, in spite of an environment fraught with hostility, disrespect and the lack of control [21]. Moreover, organizational empowerment was significantly positively associated with total job satisfaction [22] [23], because nurse assistance faced challenges in caring for the increased number of older people with cognitive impairment and their perspectives towards their work in the changing environment [24]. Managers play a critical role in the satisfaction, loyalty and commitment of their staff by supporting a person-centered workplace that deepens staff engagement; and engaged staff promote the well-being of the residents [25]. To enhance quality of elderly care, study results showed that healthy nurse work conditions (e.g. balanced job demands and job control) reduced restrains use (physical as well antipsychotic) in residential aged care [26], because nursing staff had more possibilities for skill usage and decision-making. Moreover, providing more dementia care training and reducing job demands and job strain may help to reduce work-related stress and physical assault of nurse aides employed in nursing homes [27] [28]. Working environment becomes increasingly challenging by the growing number of people with dementia and consequent heavier workload. Authors of a recently performed study argue to train professional caregivers working in long-term care settings and that how to maximize the quality of client interaction while keeping burnout and mental health problems to a minimum [29].

Our previous research showed associations between the nurse practice environment factors of nurse-physician relations, nursing management, and hospital management level with burnout dimensions, job outcomes, and quality of care variables studying both hypothetic models (e.g. structural equation modeling) and unit level analyses (e.g. multilevel modeling) [18] [30] [31]. In addition, unit-level predictions on job outcomes, quality of 
care, and patient adverse events were shown [17] [32] [33]. At the moment, research using these methodologies in geriatric care seems to be not available. The questions rises to what extent nurses perceive these aspects in geriatric care. Knowing that the mentioned perceived aspects are not only induced by individual experience, but also experiences within units and hospitals, it can be questioned what the impact across residential aged care services may be? Therefore, the aim of this study was to investigate the impact of nurse practice environment factors, nurse work characteristics, and burnout on nurse reported job outcomes, quality of care and patient adverse events across residential aged care services.

\section{Methods}

\subsection{Study Population}

A cross-sectional study was conducted in 25 residential aged care services, with mean number of beds across services of 109 (p25: 71 - p75: 128), in the Dutch speaking part of Belgium (Flanders). The residential aged care services were voluntarily involved in a project to evaluate and benchmark study results. Registered nurses (RN), licensed practical nurses (LPN) and nurse aides (NA) were invited by a coordinator/contact person at each institution to voluntarily complete the questionnaires between June and October 2012. The total study sample was 709 nurses with a mean response rate across services of 55\% (p25: 38\% - p75: 69\%) and mean number respondents of 59 (p25: 38 - p75: 69).

\subsection{Variables and Instruments}

Measures were selected from our previous research studying the impact of nurse practice environment, nurse work characteristics, and burnout on nurse-reported job outcomes, quality of care, and patient adverse events with nurse population of acute care and psychiatric care hospitals.

The Nursing Work Index Revised (NWI-R) [34] [35] was adapted previously for our samples tapping three dimensions nurse-physician relations (3 items), nursing management at the unit level (13 items), and hospital or top-level management and organizational support (15 items) [36]. Respondents rated various statements on a 4-point Likert scale from strongly disagree to strongly agree.

Three instruments assessed the nurse work characteristics; perceived workload, decision latitude, and social capital. Nurse-perceived workload was observed with a six-item intensity of labour scale [37]. Decision latitude was measured with a seven-item scale assessing participants' ability to make decisions, be creative, and use and develop their professional and personal skills at the workplace [37]. Social capital was measured with a six-item scale measuring participants' shared values and perceived mutual trust within teams and organizations [38] [39]. Respondents rated each nurse work characteristic scale item on a four-point scale from strongly disagree to strongly agree.

The Maslach Burnout Inventory Human Services Survey (MBI-HSS) [40] [41] is a three-construct measure including emotional exhaustion (eight items), depersonalization (five items) and personal accomplishment (seven items). Respondents rated their experience of various job-related feelings on a seven-point Likert scale ranging from never to every day.

Nurse-reported job outcomes were assessed using two items: satisfaction with the current job (very dissatisfied, dissatisfied, satisfied, very satisfied) and intention to leave the service within a year (yes, no). Nurse-assessed quality of care was measured with three items: at the current unit, the last shift (poor, fair, good, excellent), and in the service within the last year (definitely deteriorated, deteriorated, improved, definitely improved).

Adverse patient events were studied including patient and family complaints, patient falls, urinary tract infections, and medication errors [12] [42]. Nurses were asked to rate the frequency of these events on a four-point Likert scale (less than once a month, several times a month, several times a week or daily).

Confirmatory factor analyses and reliability and consistency of all multi-items scales were sufficient (comparative fit index $>0.90$, incremental fit index $>0.90$, root square error of approximation $<0.08$ and Cronbach's alpha coefficients ranged from 0.65 to 0.90 ). These results are comparable with results of previous acute care and psychiatric care study populations [18] [30] [31]. Moreover, associations between variables were sufficient tested using structural equation modeling (CFI and IFI 0.92; RMSEA 0.042) with the study population based on a previous studied model with a nurse population of acute care hospitals [31]: nurse practice environment di- 
mensions predicted nurse reported job outcomes and quality of care with nurse work characteristics and burnout dimensions in a mediating position respectively. The variance of both outcomes variables explained by the model was $60 \%$.

Higher scores on study results indicate stronger agreement or more favourable ratings with the exception of the indicators of workload, emotional exhaustion, depersonalization, and patient adverse events (e.g. patient and family complaints, patient falls, pulmonary and urine tract infections, and medication errors). Higher scores in these scales signify a heavier burden and/or poorer conditions. High and low unit-level mean scores for each burnout dimension were calculated based on norms (mean values) described by Schaufeli and Van Dierendonck [41].

\subsection{Ethical Approval}

The board of executives of all studied residential aged care services approved the study.

\subsection{Data Analysis}

Descriptive statistics and intra-class correlation coefficients (ICC) were examined. The degree of homogeneity of observations within residential aged care services of each measure was indicated by ICCs [32] [43] [44].

Multilevel modelling was used to investigate the residential aged care service level effect of nurse practice environment, nurse work characteristics, and burnout on nurse-reported job outcomes, quality of care, and patient adverse events. Based on previous studies, nurse practice environment dimensions, nurse work characteristics and burnout were treated as independent variables [17] [32].

Conventional regression analyses ignores the correlated structure of the observations on clustered data because they underestimate standard errors and increase the likelihood of a false rejection of the null hypothesis or acceptance of a relationship when in fact it does not exist (Type I error). Meanwhile, a two-level model incorporating a nested structure of staff members within residential aged care services corrects for the dependency of observations. Therefore, the effects of the independent variables on the dependent variables were tested with two-level linear mixed effects models with a random intercept. Level One involved variables relating to the staff members on a given residential aged care service, and Level Two involved variables relating to the residential aged care service [43].

Generalized linear mixed effects models were fitted analysing discrete dependent variables (simple multilevel models). To determine optimal predictive models, the final models were assessed with backward procedures dropping variables not improving goodness of fit (multiple multilevel models). Coefficients for all the independent measures were estimated in both unadjusted models as well as models adjusted for several nurse characteristics that had significant associations with at least one of the dependent variables. This was done in an attempt to adjust for potential confounders such as age, years working in nursing, years on the present unit, gender, diploma and work schedule as we applied in previous studies [18] [32]. The Statistical Package for the Social Sciences (SPSS Inc., Chicago) version 20.0 software was used for the descriptive analysis, and PROC MIXED and PROC NLMIXED under SAS 9.2 (SAS Institute Inc., Cary, NC) were used to fit the multilevel models.

\section{Results}

\subsection{Descriptive Analysis}

The mean age across settings was 38.0 years (p25: 34.5; p75: 40.6), the mean years in nursing was 13.3 (p25: 11.7; p75: 18.3), and the mean years on the current unit was 7.8 (p25: 5.2; p75: 11.1). The majority of studied participants were female nurses (mean 95.0\%; p25: 90.5\%; p75: 100.0\%) and on average 55.5\% (p25: 41.4\%; p75: 67.7\%) worked $80 \%$ or more of a full-time position. On average $29.8 \%$ (p25: 21.5\%; p75: 37.7\%) was RNs, 58.1\% (p25: 47.6\%; p75: 64.5\%) was LPNs and 12.1\% (p25: 5.1\%; p75: 19.8\%) was NAs. Table 1 summarizes descriptive analysis of study variables across services $(\mathrm{N}=25)$.

Nurse management at the unit level had high and most favourable mean scores in comparison with nurse-physician relations and residential aged care service management, respectively. Decision latitude had high and more favourable mean score in comparison with social capital and workload were rated predominately unfavourable. On average about $10 \%$ of respondents across residential aged care services were (very) dissatisfied with the current job and about $12 \%$ had the intentions to leave the service. Nurse-perceived quality of care at the unit and during the latest shift was reported as good or excellent, while quality of care in the setting within the 
Table 1. Characteristics and ICC values of the residential aged care services $(\mathrm{N}=25)$.

\begin{tabular}{|c|c|c|c|c|c|}
\hline & ICC & Mean & SD & p25 & p75 \\
\hline Nurse physician relations (mean)\# & 0.13 & 2.84 & 0.22 & 2.73 & 2.94 \\
\hline Nurse management at the unit-level (mean)\# & 0.22 & 2.96 & 0.21 & 2.78 & 3.11 \\
\hline Long-term care setting management \& organizational support (mean)\# & 0.22 & 2.69 & 0.27 & 2.52 & 2.86 \\
\hline Workload (mean)\# & 0.14 & 2.79 & 0.26 & 2.65 & 2.97 \\
\hline Social capital (mean)\# & 0.14 & 2.84 & 0.28 & 2.64 & 3.03 \\
\hline Decision latitude (mean)\# & 0.04 & 2.97 & 0.11 & 2.91 & 3.06 \\
\hline Emotional exhaustion (mean)\#\# & 0.07 & 1.72 & 0.37 & 1.48 & 2.01 \\
\hline Depersonalization (mean)\#\# & 0.02 & 1.03 & 0.22 & 0.89 & 1.20 \\
\hline Personal accomplishment (mean)\#\# & 0.03 & 4.39 & 0.25 & 4.23 & 4.56 \\
\hline Job satisfaction (strongly satisfied - satisfied) (\%) (a) & 0.06 & 90.1 & 7.1 & 85.6 & 95.0 \\
\hline Intention to leave the setting (no) (\%) (b) & 0.08 & 88.5 & 10.7 & 81.5 & 96.2 \\
\hline Quality of care at the current unit (excellent - good) (\%) (c) & 0.34 & 78.7 & 20.6 & 61.6 & 94.1 \\
\hline Quality of care at the last shift (excellent - good) (\%) (c) & 0.12 & 83.7 & 10,7 & 72.7 & 92.1 \\
\hline Quality of care in the setting the last year (definitely improved - improved) (\%) (d) & 0.26 & 69.7 & 21.7 & 51.5 & 88.0 \\
\hline Patient \& family complaints (less than once a month) (\%) (e) & 0.04 & 64.8 & 16.9 & 52.5 & 75.7 \\
\hline Patient falls (less than once a month) (\%) (e) & 0.15 & 62.1 & 21.4 & 50.4 & 82.1 \\
\hline Pulmonary infections (less than once a month) (\%) (e) & 0.07 & 41.4 & 17.9 & 27.8 & 55.0 \\
\hline Urinary tract infections (less than once a month) (\%) (e) & 0.06 & 49.1 & 15.2 & 38.6 & 59.7 \\
\hline Medication errors (less than once a month) (\%) (e) & 0.17 & 33.3 & 20.4 & 16.4 & 49.2 \\
\hline
\end{tabular}

ICC: Inter-class correlations; \# Scale range from 1 - 4; \#\# Scale range form 0 - 6; mean value: higher scores on study measures indicate stronger agreement or more favourable ratings with the exception of the indicators of workload, emotional exhaustion, and depersonalization. (a) Strongly satisfied or satisfied versus dissatisfied or strongly dissatisfied; (b) No, intention to leave versus yes, intention to leave; (c) Excellent or good versus fair or poor; (d) Definitely improved or improved versus deteriorated or definitely deteriorated; (e) Less than once a month versus several times a month, several times a week or daily.

last year and patient/family complaints were reported less favourable. Frequency of patient adverse events, e.g. patient falls, were rated more favourably than pulmonary infections, urinary tract infections and medication errors, respectively. One out of five residential aged care services had high or very high mean values for emotional exhaustion, one out of five services had high or very high mean values on depersonalization, and eight out of six services had low or very low mean values for personal accomplishment.

The ICCs showed values ranged from 0.02 to 0.34 . Decision latitude, burnout dimensions, intention the leave the service, patient and family complaints, pulmonary and urinary tract infections had relatively lower ICCs $(<0.10)$, but the models showed sufficient significant associations across services for these variables too $(\mathrm{p}<$ $0.05)$ (Table 2).

\subsection{Multilevel Modelling}

Practice environment, work characteristics and burnout dimensions were associated (simple models; unadjusted as well as adjusted) with nurse reported job outcomes such as job satisfaction and no intention to leave the service as well as quality of care at the unit, the latest shift and in the service the last year. Identical associations were found with nurses' rated frequency of patient and family complains except for the work characteristics variable decision latitude. Practice environment dimensions were associated with nurses' rated frequency of pulmonary infections, urinary tract infections and medication error while burnout dimensions were associated with urinary tract infections and medication error except nurse-physician relations and personal accomplishment 
Table 2. Generalized linear mixed effects model—simple multilevel model with random intercept: nurse reported job outcome and quality of care and patient safety (dependent variables) and nurse practice environment dimensions (independent variables).

\begin{tabular}{cccc}
\hline $\mathrm{N}=25$ & Unadjusted & Adjusted (g) \\
\hline
\end{tabular}

\section{Satisfaction with the current job (a)}

Nurse-physician relations (f)

Nurse management at the unit level (f)

Top level management \& organizational support (f)

\section{(No) intention to leave the service (b)}

Nurse-physician relations (f)

Nurse management at the unit level (f)

Top level management \& organizational support (f)

\section{Quality of care at the current unit (c)}

Nurse-physician relations (f)

Nurse management at the unit level (f)

Top level management \& organizational support (f)

Quality of care at last shift (c)

Nurse-physician relations (f)

Nurse management at the unit level (f)

Top level management \& organizational support (f)

Quality of care in the service the last year (d)

Nurse-physician relations (f)

Nurse management at the unit level (f)

Top level management \& organizational support (f)

\section{Patient and family complaints (e)}

Nurse-physician relations (f)

Nurse management at the unit level (f)

Top level management \& organizational support (f)

\section{Patient falls (e)}

Nurse-physician relations (f)

Nurse management at the unit level (f)

Top level management \& organizational support (f)

\section{Pulmonary infections (e)}

Nurse-physician relations (f)

Nurse management at the unit level (f)

Top level management \& organizational support (f)

\section{Urine track infections (e)}

Nurse-physician relations (f)

Nurse management at the unit level (f)

Top level management \& organizational support (f)

Medication errors (e)

Nurse-physician relations (f)

Nurse management at the unit level (f)

Top level management \& organizational support (f)

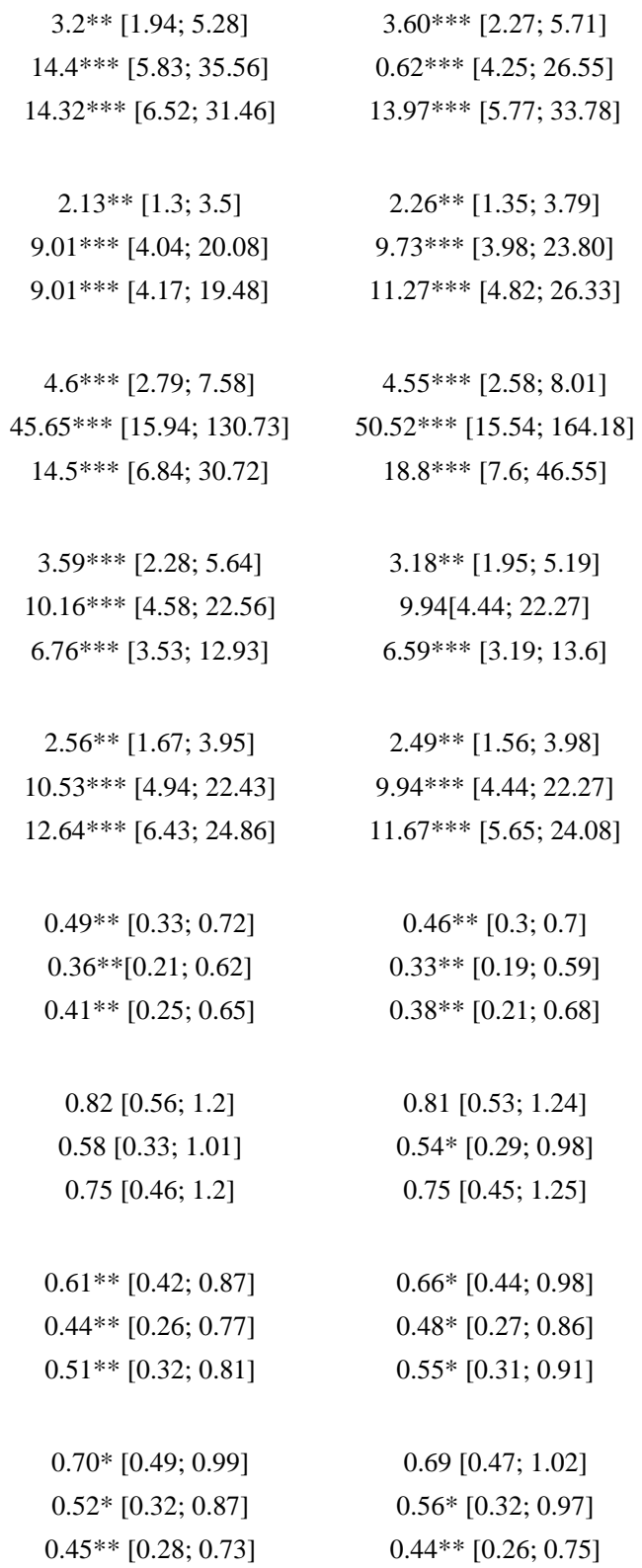

$\begin{array}{cc}0.77[0.49 ; 0.99] & 0.84[0.56 ; 1.28] \\ 0.31^{* *}[0.17 ; 0.55] & 0.3^{* *}[0.16 ; 0.57] \\ 0.37^{* *}[0.22 ; 0.62] & 0.38^{* *}[0.22 ; 0.65]\end{array}$

${ }^{* * *}$ p-value $<0.001 ; * *$ p-value $<0.01 ; *$ p-value $<0.05$; OR = Odds Ratio 95.0\% CI [lower and upper bound]; (a) Strongly satisfied or satisfied (1) versus dissatisfied or strongly dissatisfied (0); (b) No, intentiontoleave (1) versus yes, intentiontoleave (0); (c) Excellent or good (1) versus fair or poor (0); (d) Definitely improved or improved versus deteriorated or definitely deteriorated; (e) Never or few times a year (1) versus at leastonce a month, severaltimes a month, at leastonce a week, severaltimes a week or daily; (f) Meanvalue; (g) Adjusted for years in nursing —years on present unit—gender, diploma, work schedules. 
were not associated with urinary tract infections. Nurses' rated frequency of patient falls were associated with nurse management at unit level (adjusted), social capital (unadjusted), depersonalization and personal accomplishment. Nurses' rated frequency of pulmonary infections were associated with workload and emotional exhaustion and urinary tract infections were associated with workload and decision latitude (both only unadjusted) and nurses' rated medication errors were associated with workload and social capital (Table 3 and Table 4).

Table 3. Generalized linear mixed effects model-simple multilevel model with random intercept: nurse reported job outcome and quality of care and patient safety (dependent variables) and nurse work characteristics (independent variables).

\begin{tabular}{|c|c|c|}
\hline $\mathrm{N}=25$ & Unadjusted & Adjusted (g) \\
\hline & OR & OR \\
\hline \multicolumn{3}{|l|}{ Satisfaction with the current job (a) } \\
\hline Workload (f) & $0.32 * *[0.19 ; 0.54]$ & $0.34 * *[0.19 ; 0.61]$ \\
\hline Decision latitude (f) & $5.66 * *[2.61 ; 12.24]$ & $6.52 * *[2.66 ; 15.97]$ \\
\hline Social capital (f) & $4.81 * * *[3.11 ; 7.42]$ & $4.26 * * *[2.63 ; 6.91]$ \\
\hline \multicolumn{3}{|c|}{ (No) intention to leave the service (b) } \\
\hline Workload (f) & $0.29 * *[0.17 ; 0.49]$ & $0.25^{* *}[0.14 ; 0.45]$ \\
\hline Decision latitude (f) & $2.64 *[1.27 ; 5.48]$ & $2.73 *[1.23 ; 6.04]$ \\
\hline Social capital (f) & $4.04 * * *[2.61 ; 6.26]$ & $4.66^{* * *}[2.85 ; 7.64]$ \\
\hline \multicolumn{3}{|c|}{ Quality of care at the current unit (c) } \\
\hline Workload (f) & $0.28 * * *[0.18 ; 0.45]$ & $0.25^{* * *}[0.14 ; 0.43]$ \\
\hline Decision latitude (f) & $4.57 * *[2.36 ; 8.88]$ & $4.68^{* *}[2.15 ; 10.18]$ \\
\hline Social capital (f) & $6.87 * * *[4.3 ; 10.96]$ & $7.72 * * *[4.4 ” ; 13.45]$ \\
\hline \multicolumn{3}{|l|}{ Quality of care at last shift (c) } \\
\hline Workload (f) & $0.33 * * *[0.21 ; 0.52]$ & $0.3^{* *}[0.18 ; 0.51]$ \\
\hline Decision latitude (f) & $5.24 * * *[2.65 ; 10.33]$ & $5.95^{* * *}[2.73 ; 12.97]$ \\
\hline Social capital (f) & $4.48^{* * *}[3 ; 6.69]$ & $4.13^{* * *}[2.66 ; 6.43]$ \\
\hline \multicolumn{3}{|c|}{ Quality of care in the service the last year (d) } \\
\hline Workload (f) & $0.19 * * *[0.12 ; 0.3]$ & $0.22 * * *[0.14 ; 0.36]$ \\
\hline Decision latitude (f) & $2.32 * *[1.33 ; 4.05]$ & $3.1^{* *}[1.63 ; 5.89]$ \\
\hline Social capital (f) & $2.46^{* * *}[1.73 ; 3.49]$ & $2.49 * *[1.7 ; 3.66]$ \\
\hline \multicolumn{3}{|l|}{ Patient and family complaints (e) } \\
\hline Workload (f) & $1.92 * *[1.36 ; 2.71]$ & $1.99 * *[1.37 ; 2.9]$ \\
\hline Decision latitude (f) & $0.74[0.46 ; 1.19]$ & $0.71[0.42 ; 1.2]$ \\
\hline Social capital (f) & $0.56 * *[0.42 ; 0.76]$ & $0.61 * *[0.44 ; 0.84]$ \\
\hline \multicolumn{3}{|l|}{ Patient falls (e) } \\
\hline Workload (f) & $1.42[1 ; 2.01]$ & $1.41[0.96 ; 2.08]$ \\
\hline Decision latitude (f) & $1.04[0.64 ; 1.68]$ & $0.97[0.56 ; 1.66]$ \\
\hline Social capital (f) & $0.71 *[0.52 ; 0.96]$ & $0.77[0.79 ; 1.08]$ \\
\hline \multicolumn{3}{|l|}{ Pulmonary infections (e) } \\
\hline Workload (f) & $1.43 *[1.03 ; 2.01]$ & $1.5^{*}[1.04 ; 2.17]$ \\
\hline Decision latitude (f) & $0.72[0.45 ; 1.15]$ & $0.85[0.5 ; 1.42]$ \\
\hline Social capital (f) & $0.88[0.67 ; 1.17]$ & $0.84[0.61 ; 1.15]$ \\
\hline \multicolumn{3}{|l|}{ Urinary track infections (e) } \\
\hline Workload (f) & $1.47 *[1.06 ; 2.04]$ & $2.08[1.39 ; 3.12]$ \\
\hline Decision latitude (f) & $0.61 *[0.39 ; 0.97]$ & $0.65[0.39 ; 1.09]$ \\
\hline Social capital (f) & $0.79[0.6 ; 1.04]$ & $0.75[0.55 ; 1.03]$ \\
\hline \multicolumn{3}{|l|}{ Medication errors (e) } \\
\hline Workload (f) & $2.14 * *[1.49 ; 3.09]$ & $1.5^{* *}[1.04 ; 2.17]$ \\
\hline Decision latitude (f) & $0.82[0.5 ; 1.34]$ & $0.9[0.52 ; 1.56]$ \\
\hline Social capital (f) & $0.46 * * *[0.34 ; 0.63]$ & $0.48 * *[0.34 ; 0.67]$ \\
\hline
\end{tabular}

***p-value $<0.001$; **p-value $<0.01 ; *$ p-value $<0.05$; OR = Odds Ratio $95.0 \%$ CI [lower and upper bound]; (a) Strongly satisfied or satisfied (1) versus dissatisfied or strongly dissatisfied (0); (b) No, intentiontoleave (1) versus yes, intentiontoleave (0); (c) Excellent or good (1) versus fair or poor (0); (d) Definitely improved or improved versus deteriorated or definitely deteriorated; (e) Never or few times a year (1) versus at leastonce a month, severaltimes a month, at leastonce a week, severaltimes a week or daily; (f) Meanvalue; (g) Adjusted for years in nursing—years on present unit—gender, diploma, work schedules. 
Table 4. Generalized linear mixed effects model—simple multilevel model with random intercept: nurse reported job outcome and quality and patient safety (dependent variables) and burnout (independent variables).

\begin{tabular}{cccc}
\hline $\mathrm{N}=25$ & Unadjusted & Adjusted (g) \\
\hline & OR & OR \\
\hline
\end{tabular}

\section{Satisfaction with the current job (a)}

Emotionalexhaustion (f)

$$
\begin{gathered}
0.39 * * *[0.29 ; 0.51] \\
0.48 * *[0.35 ; 0.66]
\end{gathered}
$$

Depersonalization (f)

Personal accomplishment (f)

(No) intention to leave the service (b)

Emotionalexhaustion (f)

Depersonalization (f)

Personal accomplishment (f)

Quality of care on the current unit (c)

Emotionalexhaustion (f)

Depersonalization (f)

Personal accomplishment (f)

\section{Quality of care at last shift (c)}

Emotionalexhaustion (f)

Depersonalization (f)

Personal accomplishment (f)

Quality of care in the servicethe last year (d)

Emotionalexhaustion (f)

Depersonalization (f)

Personal accomplishment (f)

Patient and family complaints (e)

Emotionalexhaustion (f)

Depersonalization (f)

Personal accomplishment (f)

\section{Patient falls(e)}

Emotionalexhaustion (f)

Depersonalization (f)

Personal accomplishment (f)

Pulmonary infections (e)

Emotionalexhaustion (f)

Depersonalization (f)

Personal accomplishment (f)

Urinary track infections (e)

Emotionalexhaustion (f)

Depersonalization (f)

Personal accomplishment (f)

Medication errors (e)

Emotionalexhaustion (f)

Depersonalization (f)

Personal accomplishment (f)$$
1.4 *[1.02 ; 1.93]
$$

$$
\begin{gathered}
0.38 * * *[0.28 ; 0.52] \\
0.55 * *[0.39 ; 0.77] \\
1.55 *[1.08 ; 2.22]
\end{gathered}
$$

$0.35 * * *[0.25 ; 0.49]$

$0.54 * *[0.4 ; 0.73]$

$0.6^{* *}[0.43 ; 0.83]$

$1.61 * *[1.17 ; 2.24]$

$1.62 *[1.13 ; 2.31]$

$0.52 * * *[0.41 ; 0.66]$

$0.55 * *$ [0.42; 0.72]

$0.59 * *$ [0.45; 0.77]

$0.62 * *$ [0.45; 0.86]

$1.65 * *[1.25 ; 2.18]$

$1.72 * *[1.24 ; 2.38]$

$0.45 * * *$ [0.35; 0.57]

$0.47 * * *$ [0.36; 0.61]

$0.5 * * *[0.38 ; 0.66]$

$0.54 * *[0.4 ; 0.74]$

$1.72 * *[1.3 ; 2.27]$

$1.88 * *[1.37 ; 2.58]$

$0.48 * * *[0.38 ; 0.61]$

$0.49 * * *[0.38 ; 0.63]$

$0.6 * *[0.46 ; 0.78]$

$0.64 * *[0.48 ; 0.86]$

$1.31 *[1.02 ; 1.68]$

$1.36 *[1.03 ; 1.8]$

$1.46 * *[1.2 ; 1.78]$

$1.36 * *$ [1.09; 1.68$]$

$1.44 *$ [1.09; 1.89]

$0.77 *[0.6 ; 0.99]$

$0.7 * *[0.56 ; 0.89]$

1.11 [0.9; 1.36]

$1.37 *[1.04 ; 1.8]$

$0.68 * *$ [0.52; 0.88]

$0.66 * *$ [0.52; 0.84]

$1.25 *$ [1.04; 1.50$]$

$1.24 *[1.01 ; 1.51]$

1.08 [0.85; 1.39]

0.94 [0.73; 1.19]

$0.88[0.71 ; 1.09]$

$1.24 *[1.01 ; 1.52]$

$1.41 *[1.08 ; 1.82]$

0.84 [0.66; 1.08]

$0.77 *[0.62 ; 0.96]$

$1.49 * *$ [1.23; 1.82$]$

$1.38 * *[1.11 ; 1.71]$

$1.78 * *$ [1.39; 2.66]

$1.67 * *[1.27 ; 2.2 \&]$

$0.67 * *$ [0.53; 0.84]
$0.68 * *$ [0.52; 0.87]

***p-value $<0.001 ;{ }^{* *}$ p-value $<0.01 ; *$ p-value $<0.05$; OR = Odds Ratio 95.0\% CI [lower and upper bound]; (a) Strongly satisfied or satisfied (1) versus dissatisfied or strongly dissatisfied (0); (b) No, intentiontoleave (1) versus yes, intentiontoleave (0); (c) Excellent or good (1) versus fair or poor (0); (d) Definitely improved or improved versus deteriorated or definitely deteriorated; (e) Never or few times a year (1) versus at leastonce a month, severaltimes a month, at leastonce a week, severaltimes a week or daily; (f) Meanvalue; (g) Adjusted for years in nursing—years on present unit—gender, diploma, work schedules. 
Multiple models showed the strongest predictors. Job satisfaction and no intention to leave the service were both predicted by social capital, and the first outcome variable additionally with nurse-physicians relations (unadjusted), decision latitude and depersonalization, while the second outcome variable additionally by emotional exhaustion. Quality of care variables were predicted by nurse management at the unit level and social capital, while quality of care at the unit was predicted additionally by workload and personal accomplishment, quality of care during the latest shift additionally with decision latitude and depersonalisation, and quality of care in the service within the last year additionally with workload and emotional exhaustion. Nurses' rated frequency of adverse patient events such as patient and family complains and pulmonary infections were predicted by nurse management at the unit level, and the first additionally by depersonalization, patient falls by personal accomplishment and urinary tract infections by top-level management (Table 5).

Table 5. Final generalized linear mixed effects model-multiple multilevel model with random intercept: nurse reported job outcome and quality of care and patient safety (dependent variables) and nurse practice environment, nurse work characteristics and burnout (independent variables).

\begin{tabular}{|c|c|c|}
\hline $\mathrm{N}=25$ & Unadjusted & Adjusted (g) \\
\hline & OR & OR \\
\hline \multicolumn{3}{|l|}{ Satisfaction with the current job (a) } \\
\hline Nurse-physician relations (f) & $2.09 *[1.08 ; 4.01]$ & $1.81[0.87 ; 3.75]$ \\
\hline Social capital (f) & $2.28 *[1.36 ; 3.81]$ & $3.62 * * *[2.22 ; 5.88]$ \\
\hline Decision latitude (f) & $2.52 *[1.07 ; 5.93]$ & $3.75 *[1.50 ; 9.39]$ \\
\hline Depersonalization (f) & $0.62 *[0.43 ; 0.89]$ & $0.59 *[0.41 ; 0.85]$ \\
\hline \multicolumn{3}{|l|}{ (No) intention to leave the service (b) } \\
\hline Social capital (f) & $2.68^{* *}[1.63 ; 4.4]$ & $3.26 * *[1.84 ; 5.78]$ \\
\hline Emotional exhaustion (f) & $0.41 * * *[0.3 ; 0.55]$ & $0.36 * * *[0.26 ; 0.51]$ \\
\hline \multicolumn{3}{|l|}{ Quality of care on the current unit (c) } \\
\hline Nurse management at the unit level (f) & $11.56^{* *}[3.7 ; 36.08]$ & $10.35 * *[3.03 ; 35.34]$ \\
\hline Workload (f) & $0.5^{*}[0.27 ; 0.93]$ & $0.38 *[0.18 ; 0.78]$ \\
\hline Social Capital (f) & $2.95^{* *}[1.61 ; 5.41]$ & $3.03^{* *}[1.53 ; 6.02]$ \\
\hline Personal accomplishment (f) & $1.51 *[1.01 ; 2.27]$ & $1.62[0.99 ; 2.63]$ \\
\hline \multicolumn{3}{|l|}{ Quality of care at last shift (c) } \\
\hline Nurse management at the unit level (f) & $3.15 *[1.15 ; 8.66]$ & $2.90 *[1.02 ; 8.20]$ \\
\hline Decision latitude (f) & $2.65 *[1.13 ; 6.22]$ & $3.49 *[1.33 ; 9.12]$ \\
\hline Social capital (f) & $2.78^{* *}[1.62 ; 4.76]$ & $2.81 *[1.58 ; 5.00]$ \\
\hline Depersonalization (f) & $0.56 *[0.39 ; 0.81]$ & $0.58 *[0.38 ; 0.87]$ \\
\hline \multicolumn{3}{|l|}{ Quality of care in the service the last year (d) } \\
\hline Nurse management at the unit level (f) & $5.86 * *[2.64 ; 13]$ & $5.76 * *[2.45 ; 13.53]$ \\
\hline Workload (f) & $0.3^{* *}[0.17 ; 0.52]$ & $0.34^{* *}[0.19 ; 0.62]$ \\
\hline Emotional exhaustion (f) & $0.74 *[0.54 ; 1]$ & $0.75[0.54 ; 1.03]$ \\
\hline \multicolumn{3}{|l|}{ Patient and family complaints (e) } \\
\hline Nurse management at the unit level (f) & $0.36^{* *}[0.21 ; 0.63]$ & $0.4^{* *}[0.22 ; 0.73]$ \\
\hline Depersonalization (f) & $1.72 * *[1.28 ; 2.29]$ & $1.38 *[1 ; 1.9]$ \\
\hline \multicolumn{3}{|l|}{ Patient falls (e) } \\
\hline Personal accomplishment (f) & $0.66^{* *}[0.52 ; 0.84]$ & $0.68^{* *}[0.52 ; 0.88]$ \\
\hline \multicolumn{3}{|l|}{ Pulmonary infections (d) } \\
\hline Nurse management at the unit level (f) & $0.44 * *[0.26 ; 0.77]$ & $0.48^{*}[0.27 ; 0.86]$ \\
\hline \multicolumn{3}{|l|}{ Urinary tract infections (e) } \\
\hline Top level management \& organizational support (f) & $0.42 * *[0.23 ; 0.76]$ & $0.38 * *[0.19 ; 0.75]$ \\
\hline \multicolumn{3}{|l|}{ Medication errors (e) } \\
\hline Workload (f) & $2.11^{* *}[1.43 ; 3.12]$ & $2.06^{* *}[1.34 ; 3.18]$ \\
\hline Social capital (f) & $0.49 * *[0.35 ; 0.67]$ & $0.51^{* *}[0.36 ; 0.73]$ \\
\hline
\end{tabular}

***p-value < 0.0001; **p-value < 0.001; *p-value < 0.05; OR = Odds Ratio 95.0\% CI [lower and upper bound]; (a) Strongly satisfied or satisfied (1) versus dissatisfied or strongly dissatisfied (0); (b) No, intentiontoleave (1) versus yes, intentiontoleave (0); (c) Excellent or good (1) versus fair or poor (0); (d) Definitely improved or improved versus deteriorated or definitely deteriorated; (e) Never or few times a year (1) versus at leastonce a month, severaltimes a month, at leastonce a week, severaltimes a week or daily; (f) Meanvalue; (g) Adjusted for years in nursing—years on present unit—gender, diploma, work schedules. 


\section{Discussion}

Associations between nurse practice environment aspects, work characteristics, burnout and quality of care and patient adverse events were found across residential aged care services. Strong predictors were nursing management at the unit level, workload, decision latitude, social capital, emotional exhaustion, and depersonalization.

Our results across services are in line with results of other studies. McGilton et al. [45] found various predictors on intention to stay identified with a study population of 155 nurses of 11 residential aged care services. Intention to stay was positively associated with lower burnout, higher job satisfaction and resident relationships. Work relationships were negatively associated with intention to stay. Another study-with a sample of 657 nursing and other staff-found that fostering positive work group cohesion, supporting and acknowledging staff accomplishments and minimizing staff burnout were related to job satisfaction and intention to stay [46]. Li et al. [47] found that both psychological and structural empowerment positively correlated with job satisfaction among nurses in residential aged care services. Moreover, the structural empowerment had a mediating effect on job satisfaction.

Our studies results showed the importance of different organizational levels within health care facilities as well interdisciplinary relations. Because of the difficulty to recruit and retain nurses in residential aged care services a project of 80/20 staffing model was recently set up by the Newfoundland and Labrador's Central Regional Health Authority in Canada [48]. The model allows nurse participants (6 RNs and 1 LPN) to spend 20\% of their paid time pursuing a professional development activity instead of providing direct patient care. The aim of the project is to increase capacity for RN leadership, training and support and to enhance the profile of long-term care as a place to work because the increasing acuity of long-term care residents and their complex care needs. Additional initiative will be taken to continue a 90/10 model for one RN and one LPN per semester to evaluate this alternative staffing model and the feasibility of implementing in other sites throughout the region. Another initiative in Canada funded a nurse leader in long-term care training program and a mentor team program to foster a positive nurses' work life providing them with skills and knowledge to lead the care team and to address resident and family issues. Results showed that not only individual nurses benefited from taking part in these programs, but also other parts of residential aged care services [49]. The authors concluded that a generally healthier work environment—as anticipated in these programs—-would have a positive effect on recruitment and retention. Stabile and supported workforce is imperative to offer excellent care and patient safety for a vulnerable and frail patient population, a responsibility of all stakeholders such as executives, leaders, physicians as well as nurses.

\section{Conclusion}

Our studies found variation across residential aged care services about perceived nurse practice environment, work characteristics, feelings of burnout and the impact on nurse and patient outcomes. Residential aged care services are challenged with complexity of care in a certain socio-economic context. Recruitment, training and retaining health care workers offering the best care for patients and families with specific needs require a supportive and healthy practice environment. Disseminating best practices within geriatric care can learn lessons.

\section{Limitations}

Certain limitations are mentioned. We recommend interpreting these results carefully for common method bias such as cross-sectional design and voluntarily participation of residential aged care services instead of randomized selection. Moreover, replication with a broader sample in different socio-economic contexts and welldeveloped interventions within residential aged care services guided with longitudinal design might offer valuable perspectives. Studying objective well-chosen quality and patient safety outcomes instead of nurse perceived outcome variables could confirm and extend studied predictors.

\section{Conflict of Interest}

None declared.

\section{References}

[1] Choi, J., Bakken, S., Larson, E., Du, Y. and Stone, P. (2004) Perceived Nursing Work Environment of Critical Care 
Nurses. Nursing Research, 53, 370-378. http://dx.doi.org/10.1097/00006199-200411000-00005

[2] Estabrooks, C., Tourangeau, A., Humphrey, C., Hesketh, K., Gioviannetti, P., Thomson, D., Wong, J., Acorn, S., Clarke, H. and Shamian, J. (2002) Measuring the Hospital Practice Environment: A Canadian Context. Research in Nursing \& Health, 25, 256-268. http://dx.doi.org/10.1002/nur.10043

[3] Gunnarsdóttir, S., Clark, S., Rafferty, A.M. and Nutbeam, D. (2007) Front-Line Management, Staffing and NurseDoctor Relationship as Predictors of Nurse Outcome and Patient Outcome. A Survey of Icelandic Hospital Nurses. International Journal of Nursing Studies, 46, 920-927.

[4] Li, Y., Lake, E., Sales, A., Sharp, D., Greiner, G., Low, E., Liu, C., Mitchell, P. and Sochalski, J. (2007) Measuring Nurses' Practice Environments with the Revised Nursing Work Index: Evidence form Registered Nurses in the Veterans Health Administration. Research in Nursing and Health, 30, 31-44. http://dx.doi.org/10.1002/nur.20172

[5] Schubert, M., Clarke, S., Glass, T., Schaffert-Witfield, B. and De Geest, S. (2009) Identifying Thresholds for Relationships between Impacts of Rationing of Nursing Care and Nurse- and Patient-Reported Outcomes in Swiss Hospitals: A Correlational Study. International Journal of Nursing Studies, 46, 884-893. http://dx.doi.org/10.1016/j.ijnurstu.2008.10.008

[6] Rafferty, A.M, Ball, J. and Aiken, L. (2001) Are Teamwork and Professional Autonomy Compatible and Do They Result in Improved Hospital Care? Quality in Health Care, 10, ii32-ii37.

[7] Vahey, D.C., Aiken, L.H., Sloane, D.M., Clarke, S.P. and Vargas, D. (2004) Nurse Burnout and Patient Satisfaction. Medical Care, 42, 57-66. http://dx.doi.org/10.1097/01.mlr.0000109126.50398.5a

[8] Kowalski, C., Ommen, O., Driller, E., Ernstmann, N., Wirtz, A.M., Köhler, T. and Pfaff, H. (2010) Burnout in Nurses-The Relationship between Social Capital in Hospitals and Emotional Exhaustion. Journal of Clinical, 19, 1654-1663.

[9] Leiter, P. and Maslach, C. (2009) Nurse Turnover: The Mediating Role of Burnout. Journal of Nursing Management, 17, 331-339. http://dx.doi.org/10.1111/j.1365-2834.2009.01004.x

[10] Aiken, L., Clarke, S., Sloane, D., Lake, E. and Cheney, T. (2008) Effects of Hospital Care Environment on Patient Mortality and Nurse Outcome. Journal of Nursing Administration, 38, 223-229.

http://dx.doi.org/10.1097/01.NNA.0000312773.42352.d7

[11] Friese C., Lake, E., Aiken, L., Silber, J. and Sochalski, J. (2008) Hospital Nurse Practice Environment and Outcomes for Surgical Oncology Patients. Health Service Research, 43, 1145-1163. http://dx.doi.org/10.1111/j.1475-6773.2007.00825.x

[12] Laschinger, H. and Leiter, M. (2006) The Impact of Nursing Work Environments on Patients Safety Outcomes. The Mediating Role of Burnout/Engagement. Journal of Nursing Administration, 36, 259-267.

http://dx.doi.org/10.1097/00005110-200605000-00019

[13] Tourangeau, A., Coghlan, A., Shamian, J. and Evans, S. (2005) Registered Nurse and Registered Practical Nurse Evaluations of Their Hospital Practice Environments and Their Response of These Environment. Nursing Research, 18, 54-69.

[14] Roche, M. and Duffieldj, C. (2009) A Comparison of the Nursing Practice Environment in Mental Health and Medical-Surgical Settings. Journal of Nursing Scholarship, 42, 195-206.

http://dx.doi.org/10.1111/j.1547-5069.2010.01348.x

[15] Hanrahan, N., Aiken, L., McClaine, L. and Hanlon, L. (2010) Relationship between Psychiatric Nurse Work Environment and Nurse Burnout in Acute Care General Hospitals. Issues in Mental Health Nursing, 31, 198-207. http://dx.doi.org/10.3109/01612840903200068

[16] Hanrahan, N., Kumar, A. and Aiken, L. (2010) Adverse Events Associated with Organizational Factors of General Hospital Inpatient Psychiatric Care Environment. Psychiatric Services, 61, 569-574.

http://dx.doi.org/10.1176/appi.ps.61.6.569

[17] Van Bogaert, P., Clarke, S., Wouters, K, Franck, E., Willems, R. and Mondelaers, M. (2013) Impacts of Unit-Level Nurse Practice Environment, Workload and Burnout on Nurse-Reported Outcomes in Psychiatric Hospitals: A Multilevel Modelling Approach. International Journal of Nursing Studies, 50, 357-365. http://dx.doi.org/10.1016/j.ijnurstu.2012.05.006

[18] Van Bogaert, P., Clarke, S., Willems, R. and Mondelaers, M. (2013) Nurse Practice Environment, Workload, Burnout, Job Outcomes and Quality of Care in Psychiatric Hospitals: A Structural Equation Model Approach. Journal of Advanced Nursing, 69, 1515-1524. http://dx.doi.org/10.1111/jan.12010

[19] Dwyer, D. (2011) Experiences of Registered Nurses as Managers and Leaders in Residential Aged Care Facilities: A Systematic Review. International Journal of Evidence Based Healthcare, 9, 388-402.

http://dx.doi.org/10.1111/j.1744-1609.2011.00239.x

[20] Barba, B.E., Hu, J. and Efird, J. (2012) Quality Geriatric Care as Perceived by Nurses in Long-Term and Acute Care 
Settings. Journal of Clinical Nursing, 21, 833-840. http://dx.doi.org/10.1111/j.1365-2702.2011.03781.x

[21] Secrest, J., Iorio, D.H. and Martz, W. (2005) The Meaning of Work for Nursing Assistants Who Stay in Long-Term Care. Journal of Clinical Nursing, 14, 90-97. http://dx.doi.org/10.1111/j.1365-2702.2005.01282.x

[22] Kuo, H.T., Yin, T.J. and Li, I.C. (2008) Relationship between Organizational Empowerment and Job Satisfaction Perceived by Nursing Assistants at Long-Term Care Facilities. Journal of Clinical Nursing, 17, 3059-3066. http://dx.doi.org/10.1111/j.1365-2702.2007.02072.x

[23] Li, I.C., Chen, Y.C. and Kuo, H.T. (2008) The Relationship between Work Empowerment and Work Stress Perceived by Nurses at Long-Term Care Facilities in Taipei City. Journal Clinical Nursing, 17, 3050-3058. http://dx.doi.org/10.1111/j.1365-2702.2008.02435.x

[24] Sung, H.C., Chang, S.M. and Tsai, C.S. (2005) Working in Long-Term Care Settings for Older People with Dementia: Nurses’ Aides. Journal of Clinical Nursing, 14, 587-593. http://dx.doi.org/10.1111/j.1365-2702.2004.01111.x

[25] Tellis-Nayak, V.A. (2007) Person-Centered Workplace: The Foundation for Person-Centered Caregiving in LongTerm Care. Journal of American Medical Directors Association, 8, 46-54.

[26] Pekkarinen, L., Elovainio, M., Sinervo, T., Finne-Soveri, H. and Noro, A. (2006) Nursing Working Conditions in Relation to Restraint Practices in Long-Term Care Units. Medical Care, 44, 1114-1120. http://dx.doi.org/10.1097/01.mlr.0000237198.90970.64

[27] Morgan, D.G., Stewart, N.J., D’Arcy, C., Forbes, D. and Lawson, J. (2005) Work Stress and Physical Assault of Nursing Aides in Rural Nursing Homes with and without Dementia Special Care Units. Journal of Psychiatric Mental Health Nursing, 12, 347-358. http://dx.doi.org/10.1111/j.1365-2850.2005.00846.x

[28] Shinan-Altman, S. and Cohen, M. (2009) Nursing Aides' Attitudes to Elder Abuse in Nursing Homes: The Effect of Work Stressors and Burnout. Gerontologist, 49, 674-684. http://dx.doi.org/10.1093/geront/gnp093

[29] de Rooij, A.H., Luijkx, K.G., Declercq, A.G., Emmerink, P.M. and Schols, J.M. (2012) Professional Caregivers’ Mental Health Problems and Burnout in Small-Scale and Traditional Long Term Care Settings for Elderly People with Dementia in the Netherlands and Belgium. Journal American Medical Director Association, 13, 486.e7-e11.

[30] Van Bogaert, P., Meulemans, H., Clarke, S., Vermeyen, K. and Van de Heyning, P. (2009) Hospital Nurse Practice Environments, Burnout, Job Outcomes and Quality of Care: Test of a Structural Equation Model. Journal of Advanced Nursing, 65, 2175-2185. http://dx.doi.org/10.1111/j.1365-2648.2009.05082.x

[31] Van Bogaert, P., Kowalski, C., Weeks, S.M., Van heusden, D. and Clarke, S.P. (2013) The Relationship between Nurse Practice Environment, Nurse Work Characteristics, Burnout and Job Outcome and Quality of Nursing Care: A Cross-Sectional Survey. International Journal Nursing Studies, 50, 1667-1677. http://dx.doi.org/10.1016/j.ijnurstu.2013.05.010

[32] Van Bogaert, P., Roelant, E., Clarke, S., Meulemans, H. and Van de Heyning, P. (2010) Impacts of Unit-Level Nurse Practice Environment and Burnout on Nurse-Reported Outcomes: A Multilevel Modeling Approach. Journal of Clinical Nursing, 19, 1664-1674. http://dx.doi.org/10.1111/j.1365-2702.2009.03128.x

[33] Van Bogaert, P., Timmermans, O., Weeks, S.M., Van heusden, D., Wouters, K. and Franck, E. (2013) Nursing Unit Teams Matter: Impact of Unit-level Nurse Practice Environment, Nurse Work Characteristics, and Burnout on Nurse Reported Job Outcomes, and Quality of Care, and Patient Adverse Events? International Journal of Nursing Studies. (Epub ahead of print) http://dx.doi.org/10.1016/j.ijnurstu.2013.12.009

[34] Aiken, L. and Patrician, P. (2000) Measuring Organizational Traits of Hospitals: The Revised Nursing Working Index. Nursing Research, 49, 146-153. http://dx.doi.org/10.1097/00006199-200005000-00006

[35] Lake, E. (2002) Development of Practice Environment Scale of the Nursing Work Index. Research in Nursing \& Health, 25, 176-188. http://dx.doi.org/10.1002/nur.10032

[36] Van Bogaert, P., Clarke, S., Vermeyen, K., Meulemans, H. and Van de Heyning, P. (2009) Practice Environments and their Associations with Nurse-Reported Outcomes in Belgian Hospitals: Development and Preliminary Validation of a Dutch Adaptation of the Revised Nursing Work Index. International Journal of Nursing Studies, 46, 54-64. http://dx.doi.org/10.1016/j.ijnurstu.2008.07.009

[37] Richter, P., Hemmann, E., Merboth, H., Fritz, S., Hansgen, C. and Rudolf, M. (2000) Das Erleben von Arbeitsintensität und Tätigkeitsspielraum-Entwicklung und ValidierungeinesFragebogenszurorientierenden Analyse (FIT). Zeitschriftfür Arbeits- und Organisationspsychologie, 44, 129-139.

[38] Pfaff, H., Lutticke, J., Badura, B., Piekarski, C. and Richter, P. (2004) Weiche’ Kennzahlen fur das strategische Krankenhausmanagement. Stakeholderinteressen zielgerichtet erkennen und einbeziehen. Hans Huber, Bern.

[39] Ernstmann, N., Ommen, O., Driller, E., Kowalski, C., Bartholomeyczik, S. and Pfaff, H. (2009) Social Capital and Risk Management in Nursing. Journal of Nursing Care Quality, 24, 340-347. http://dx.doi.org/10.1097/NCQ.0b013e3181b14ba5

[40] Maslach, C., Jackson, S. and Leiter, P. (1996) Maslach Burnout Inventory Manual. 3rd Edition, Mountain View, Cali- 
fornia.

[41] Schaufeli, W. and Van Dierendonck, D. (2000) Handleiding van de Utrechtse Burnout Schaal (UBOS) (Manual Utrecht Burnout Scale). Swets Test Services, Lisse.

[42] Aiken, L., Sermeus, W., Van den Heede, K., Sloane, D., Busse, R., McKee, M., Bruyneel, L., Griffiths, P., MorenoCasbas, M., Tichelman, C., Scott, A., Brzokstel, T., Kinnunen, L., Schwendimann, R., Heinen, M., Zikos, D., Sjetne, I., Smith, H. and Kutney-Lee, A. (2012) Patient Safety, Satisfaction, and Quality of Hospital Care: Cross Sectional Surveys of Nurses and Patients in 12 Countries in Europe and the United States. British Medical Journal, 344, e1717, http://dx.doi.org/10.1136/bmj.e1717

[43] Fitzmaurice, G., Laird, N. and Ware, J. (2004) Applied Longitudinal Analysis. John Wiley \& Sons, Hoboken.

[44] Kreft, I. and De Leeuw, J. (1998) Introduction to Multilevel Modelling. Sage Publications, London.

[45] McGilton, K.S., Tourangeau, A., Kavcic, C. and Wodchis, W.P. (2013) Determinants of Regulated Nurses' Intention to Stay in Long-Term Care Homes. Journal Nursing Management, 21, 771-781. http://dx.doi.org/10.1111/jonm.12130

[46] Tourangeau, A., Cranley, L., Spence Laschinger, H.K. and Pachis, J. (2010) Relationships among Leadership Practices, Work Environments, Staff Communication and Outcomes in Long-Term Care. Journal Nursing Management, 18, 1060-1072. http://dx.doi.org/10.1111/j.1365-2834.2010.01125.x

[47] Li, I.C., Kuo, H.T., Huang, H.C., Lo, H.L. and Wang, H.C. (2013) The Mediating Effects of Structural Empowerment on Job Satisfaction for Nurses in Long-Term Care Facilities. Journal Nursing Management, 21, 440-448. http://dx.doi.org/10.1111/j.1365-2834.2012.01396.x

[48] Stuckless, T. and Power, M. (2012) Newfoundland and Labrador: 80/20 Staffing Model Pilot in a Long-Term Care Facility. Nursing Leadership (Toronto Ontario), Spec No. 2012, 45-50.

[49] O’Brien, J., Ringland, M. and Wilson, S. (2010) Advancing Nursing Leadership in Long-Term Care. Nursing Leadership (Toronto Ontario), Spec No. 2010, 75-89. 